\title{
Estudios
}

\section{La naturaleza como sujeto de derechos. Un breve análisis constitucional, comparado y jurisprudencial}

\section{Nature as a subject of rights. A brief constitutional, comparative, and jurisprudential analysis}

\author{
Hernán Cuéllar Muñoz ${ }^{1}$
}

Recepción: 25/09/2020 • Aprobación: 02/02/2021 • Publicación: 17/09/2021

Para citar este artículo

Cuéllar Muñoz, H. (2021). La naturaleza como sujeto de derechos. Un breve análisis constitucional, comparado y jurisprudencial. Dos mil tres mil, 23, e269. https://doi.org/10.35707/dostresmil/23269

\section{(c) $\$=$}

\footnotetext{
${ }^{1}$ Universidad Externado de Colombia, Correo electrónico: hernancuellarm@hotmailcom
} 
Resumen. El texto contiene un análisis de los fundamentos constitucionales y el derecho comparado, los cuales han justificado el activismo judicial en materia ambiental, logrando crear dentro del ordenamiento jurídico colombiano el concepto de la naturaleza como sujeto de derechos. Dicho análisis permitirá establecer el deficiente grado de pertinencia de esta declaración al tener en cuenta los conflictos que se presentan en relación con los derechos de las personas.

\begin{abstract}
The text contains an analysis of the constitutional basis and comparative law, which have justified judicial activism in environmental matters, managing to create within the Colombian legal system the concept of nature as a subject of rights. Said analysis will make it possible to establish the deficient degree of relevance of this statement when bearing in mind conflicts that arise related to people's rights.
\end{abstract}

\title{
Palabras claves
}

Ecocentrismo, antropocentrismo, recursos naturales, jurisprudencia, sujetos de derechos, conflictos.

\section{Key words}

Ecocentrism, anthropocentrism, natural resources, jurisprudence, subjects of rights, conflicts. 


\section{Introducción}

A raíz de la promulgación de la Constitución Política de Colombia en el año 1991 se originó en nuestro país un novedoso modelo de regulación ambiental; esta carta de derechos fundamentales, que decidió alterar el restrictivo modelo de Estado de derecho por un garantista Estado social de derecho, trae consigo numerosas manifestaciones de autoridad encaminadas a la protección de los ecosistemas presentes en el territorio y de la naturaleza en general.

Esta base normativa superior ha ocasionado que, dentro de las dinámicas de los diferentes sectores en Colombia, ya sea industrial, económico, salud y el mismo sector ambiental, se produzcan una serie de decisiones judiciales en materia de concesión de derechos a la naturaleza, a raíz de la preocupación de algunos grupos activistas en defensa del derecho a gozar de un ambiente sano o incluso la misma población civil sin intereses colectivos adicionales.

Con base en ello, desde el año 2016 y hasta la fecha, las altas cortes de Colombia (Corte Suprema de Justicia, Corte Constitucional y Consejo de Estado) y los Tribunales Superiores de Distrito Judicial como el Tribunal Superior de Distrito Judicial de Ibagué, luego de realizar un estudio de acciones populares y de tutela, han decidido otorgar la figura de sujeto de derechos a diferentes ecosistemas naturales. Con ocasión a eventuales amenazas a los recursos renovables y no renovables allí presentes, en razón a actividades propias del ser humano.

Al tener en cuenta lo anterior, este trabajo analizará el grado de pertinencia de la declaración de la naturaleza como un sujeto de derechos dentro del ordenamiento jurídico colombiano, con el propósito de determinar su efectividad en el deber de protección constitucional consagrado en el artículo 79 de la Constitución Política de Colombia de 1991.

Así las cosas, iniciaremos con un estudio de los conceptos de antropocentrismo y ecocentrismo en el marco de la Constitución Política de Colombia; en segundo lugar, se analizará la perspectiva del derecho comparado ambiental para determinar cuál es el estado actual de este fenómeno. A continuación, se expondrán las decisiones judiciales más relevantes en Colombia, en las que se declararon varios ecosistemas como sujetos de derechos y en último lugar expondremos, bajo los argumentos reseñados anteriormente, los conflictos que se pueden presentar entre los derechos de la naturaleza y los derechos de las personas.

\section{Las figuras de antropocentri smo y ecocentrismo en la Constitución Política de Colombia}

Para poder iniciar con el estudio de los conceptos de antropocentrismo y ecocentrismo es necesario aclarar sus definiciones; en ese orden de ideas, basta con realizar un pequeño esfuerzo de investigación para determinar que existe un sinnúmero de autores (De Sousa Abreu \& De Azevedo Bussinger, 2013; Toca Torres, 2011; Dávila García, 2011; Martínez Torvisco, 2011) que se han encargado de exponer acertadamente sus ideas. No obstante, abordaremos estas definiciones a través de lo señalado por la honorable Corte Constitucional, bajo la consideración que todos sus pronunciamientos están acoplados y ajustados a la defensa de la Carta Magna. 
Dicho esto, la Corte Constitucional ha mencionado, tratándose del concepto antropocéntrico, que:

Responde a una antigua tradición filosófica y económica - que va desde los teóricos naturalistas como Smith y Ricardo hasta los pragmáticos neoliberales como Stiegler y Friedman - que ha concebido al hombre como el único ser racional, digno y completo del planeta. Desde este punto de vista, lo único que importa es la supervivencia del ser humano y solo en esta medida debe protegerse el medio ambiente, aun cuando admite la posibilidad de la explotación controlada de recursos naturales para promover el desarrollo estatal. (Corte Constitucional de Colombia, Sentencia T-622 de 2016).

Con base en lo expuesto por la Corte Constitucional, queda claro que, frente al concepto antropocéntrico, el ser humano es el núcleo esencial en la existencia del planeta y solo habrá que regular la protección de los ecosistemas naturales que lo conforman, en la medida que su explotación garantice la supervivencia de las personas, con la salvedad planteada por el órgano de cierre constitucional, y es que su explotación debe ser controlada.

Por otro parte, frente al concepto denominado ecocentrismo, la Corte Constitucional ha dicho que:

La especie humana es solo un evento más dentro de una larga cadena evolutiva que ha perdurado por miles de millones de años y por tanto de ninguna manera es la dueña de las demás especies, de la biodiversidad ni de los recursos naturales como tampoco del destino del planeta. En consecuencia, esta teoría concibe a la naturaleza como un auténtico sujeto de derechos que deben ser reconocidos por los Estados y ejercidos bajo la tutela de sus representantes legales, verbigracia, por las comunidades que la habitan o que tienen una especial relación con ella. (Corte Constitucional de Colombia, Sentencia T-622 de 2016).

Conforme a ello, la especie humana deja de ser el elemento principal, cediendo a la importancia intrínseca de la naturaleza y, en consecuencia, desde una perspectiva ecocéntrica radical, no le sería permitida la explotación de los recursos naturales, ni siquiera bajo estándares controlados. Al tener claro los conceptos, la pregunta que surge es: ¿Cuál es la postura asumida por la Constitución Política de Colombia de 1991?

Así, los artículos constitucionales más relevantes - pues no son los únicos que buscan conservar y proteger la naturaleza en el país ${ }^{2}$ - corresponden al artículo 79 y 80 superiores, los cuales rotulan:

Artículo 79. Todas las personas tienen derecho a gozar de un ambiente sano. La ley garantizará la participación de la comunidad en las decisiones que puedan afectarlo.

Es deber del Estado proteger la diversidad e integridad del ambiente, conservar las áreas de especial importancia ecológica y fomentar la educación para el logro de estos fines.

Artículo 80. El Estado planificará el manejo y aprovechamiento de los recursos naturales, para garantizar su desarrollo sostenible, su conservación, restauración o sustitución.

\footnotetext{
${ }^{2}$ Para un estudio detallado de los artículos constitucionales que regulan temas ambientales, cfr. Amaya Navas (2016).
} 
Además, deberá prevenir y controlar los factores de deterioro ambiental, imponer las sanciones legales y exigir la reparación de los daños causados.

Así mismo, cooperará con otras naciones en la protección de los ecosistemas situados en las zonas fronterizas. (Constitución Política de Colombia, 1991).

Dicho esto, pareciera que desde el artículo 79, Colombia adoptara un modelo de protección basado en el ecocentrismo, al garantizar que la población en general tiene el derecho a gozar de un ambiente sano y además el Estado tiene la obligación de conservar los diferentes ecosistemas presentes en el territorio; sin embargo, a partir del artículo 80, se hace mención a la planificación y aprovechamiento de los recursos naturales, circunstancia aquella que contraría de manera directa la esencia de ecocentrismo, y nos ubica en la órbita del antropocentrismo, al permitir la explotación o el aprovechamiento de los recursos naturales en beneficio de los ciudadanos, con el respeto, por supuesto, de la condición establecida por la Corte Constitucional, es decir, de manera controlada.

Otro argumento que refuerza la teoría que Colombia es un país netamente antropocentrista desde las disposiciones de la Constitución, que a vista de parecer lógica tiene una gran relevancia jurídica, es que la guarda, la tutela y la conservación de la naturaleza dependen exclusivamente de la voluntad de los seres humanos; en otras palabras, dependerá de la iniciativa de los ciudadanos promover acciones como las populares o de tutela para exigir desde el aparato jurisdiccional la protección del derecho a gozar de un ambiente sano, o de los líderes políticos mediante el fomento de estrategias públicas encaminadas al mismo fin; y en ese sentido, el ser humano se convierte en la base fundamental para la conservación y para garantizar su propia existencia en el planeta.

Por otro lado, aunque esta teoría parece sencilla de comprender, existen autores que consideran que no es posible adoptar teóricamente una posición entre estos dos conceptos, pues:

Si se adopta una visión completamente concentrada en el primero (antropocentrismo), el segundo (eco centrismo) estará condenado al incesante y marcado deterioro y, por consiguiente, las personas estarán llamadas a la extinción. Y si se acoge una perspectiva plenamente basada en el medio ambiente, se estaría asumiendo una actitud hipócrita respecto del fundamento de la preocupación humana por el deterioro de la naturaleza, puesto que esta preocupación no emana del valor propio del ambiente, sino de los perjuicios que las catástrofes naturales implican para la especie humana. Lo ideal es adoptar un enfoque ecléctico que haga viable la imposición de límites rigurosos a la conducta humana en beneficio del entorno natural con base en la alta importancia que no tiene por sí mismo, sino por lo que representa para la humanidad y su futuro. (Guzmán Jiménez \& Ubajoa Osso, 2020, p. 208).

Más allá de esto, también se plantea por una parte de la doctrina que esta discusión debe ser superada, toda vez que "los problemas ambientales son de tal magnitud que resulta irrelevante debatir si se debe adoptar un modelo ecocentrista o antropocentrista" (Amaya Navas, 2016, p. 26); sin embargo, para fines prácticos, la concepción que quiso darle el legislador al modelo de 
conservación ambiental en Colombia es antropocentrista, sin que ello implique a todas luces que el aprovechamiento de los recursos naturales sea sinónimo de destrucción o deterioro, pues su principal fin es satisfacer las necesidades de las personas, bajo una mirada de control por parte del Estado, con la seguridad de que cualquier impacto que se pueda ocasionar en el ecosistema, tendrá un efecto inmediato en la vida de los seres humanos y en su subsistencia.

\section{La naturaleza como sujeto de derechos en el derecho comparado}

\subsection{Ecuador}

Uno de los ordenamientos jurídicos que más ha trabajado el concepto de la personalidad de la naturaleza es Ecuador. Allí, desde la expedición de la Constitución Política de 2008, el vecino país reconoció de manera tajante los derechos de la naturaleza. Desde una concepción subjetiva, Ecuador introdujo en su capítulo séptimo, cinco artículos en los que señala cuáles son los derechos de la naturaleza y quién será su representante legal, en el evento de presentarse acciones o hechos que impacten negativamente al ambiente. Veamos entonces, como en su artículo 71 constitucional regula:

La naturaleza o Pacha Mama, donde se reproduce y realiza la vida, tiene derecho a que se respete integralmente su existencia y el mantenimiento y regeneración de sus ciclos vitales, estructura, funciones y procesos evolutivos. Toda persona, comunidad, pueblo o nacionalidad podrá exigir a la autoridad pública el cumplimiento de los derechos de la naturaleza. Para aplicar e interpretar estos derechos se observarán los principios establecidos en la Constitución, en lo que proceda. El Estado incentivará a las personas naturales y jurídicas, y a los colectivos, para que protejan la naturaleza, y promoverá el respeto a todos los elementos que forman un ecosistema. (Constitución de la República del Ecuador, 2008).

Pareciera que el artículo 71 de la Constitución Política de Ecuador no dejara espacios para la interpretación; por el contrario, de manera soslayada parece tener instrucciones claras en tres puntos: el derecho de la naturaleza, sus representantes y la obligación del Estado de fomentar la protección del ambiente; no obstante, el mismo artículo establece que uno de sus derechos es el mantenimiento y regeneración de sus ciclos vitales, estructura, funciones y procesos evolutivos, circunstancia que revela dos grandes problemas de interpretación.

El primero de ello, porque al ser tan autorreferencial con la naturaleza, se podría incurrir en la interpretación:

[...] que la naturaleza tiene derecho a protegerse de sí misma y en segundo lugar se plantea que son las personas físicas quienes deben velar por el cumplimiento de esos derechos, teniendo en cuenta que la naturaleza como conjunto orgánico e inorgánico no puede ejercer su propia defensa. (Viciano Pastor, 2019, p. 146).

Esta base normativa ha sido el ingrediente más importante para pronunciamientos judiciales en Ecuador, en pro de salvaguardar la integridad de los derechos de la naturaleza. 
Así, por ejemplo, la acción de protección 11121-2011-0010 resulta por la Corte Provincial de la Loja de Ecuador, en un caso en el que se solicitó la protección del río Vilcabamba — cuyo cauce atravesaba por predios de particulares- por la ampliación de una carretera, de quien sin permisos ambientales vertió grandes cantidades de material de excavación: se reconoció por el juzgador la importancia de la naturaleza, a tal punto que dispuso que los daños causados a ella son daños generacionales, esto quiere decir que no solo afectan a la generación actual de seres humanos sino también a las futuras. Como si fuera poco, en esta decisión también se utilizó la inversión de la carga de la prueba, siendo la entidad accionada la obligada a desvirtuar la presencia del impacto o la amenaza a la naturaleza.

Pese a que la decisión anterior fue hito en el ordenamiento jurídico ecuatoriano, su interpretación en reconocer los derechos a la naturaleza de manera subjetiva, no es pacífica, pues se dice, especialmente, que:

Los demandantes no solo actúan en nombre y beneficio de la naturaleza como sujeto de derechos, sino que tienen intereses particulares y directamente afectados. Con ello, este primer caso demuestra la dificultad anunciada de escindir la objetivación de los derechos de la naturaleza y su ejercicio subjetivo por terceros, lo que de nuevo nos traslada al campo de los derechos ambientales. El giro biocéntrico se daría aquí más desde el punto de vista teórico o simbólico, pero en la praxis los intervinientes lo hacen porque la afectación al cauce fluvial afecta sus intereses particulares, legítimos por otra parte. (Viciano Pastor, 2019, pp. 151-152).

De aprobar la interpretación anterior, resulta factible deducir el carácter simbólico de los derechos de la naturaleza, pues si bien se protege a título de pronunciamiento el derecho constitucional de la naturaleza, su justificación se encuentra en los servicios o intereses que ella puede prestar a las personas, en el caso puntual, a los sujetos afectados por la construcción de la carretera y de paso por el incumplimiento a la normatividad ambiental vigente, pero no necesariamente por su valor intrínseco, pues no se habla del valor propio del ecosistema, sino de la afectación a los intereses de las personas con ocasión al impacto del río. Hecho que, sin duda, estaría ya regulado en los derechos de las personas a gozar de un ambiente sano, el cual también se garantiza en Ecuador. En esa medida, no se trata de oponernos anticipadamente a la declaración de la naturaleza como sujeto de derecho, pero sí precipitarnos a establecer el poco grado de pertinencia que conlleva, toda vez que en el evento de no existir tal declaración también se debe proteger el ecosistema afectado.

\subsection{Nueva Zelanda}

El caso de Nueva Zelanda, pese a no tener origen en el aparato jurisdiccional propiamente, es uno de los eventos más representativos en materia de declaración de derechos a la naturaleza, al menos así lo señalan varios medios de comunicación (El País, 2017; ввC, 2017; Semana, 2017). En este ordenamiento jurídico se optó por la adopción de una Ley denominada Te Awa Tapua -que se refiere al río como un ente viviente e indivisible-, por medio de la cual se le reconoce 
derechos al río Whanguanui a través de un acuerdo entre la población Iwi y el Estado de Nueva Zelanda, dicha Ley "establece un marco de gobernanza para los recursos naturales" (Macpherson \& O'Donnell, 2017, p. 109).

La Ley Te Awa Tapua declara que el río en mención tiene todos los derechos, deberes y responsabilidades de una persona jurídica - veamos entonces, como desde ya equipara a la naturaleza como un clásica figura del derecho-, esto implica la posibilidad que tiene de acudir al sistema judicial en defensa de los derechos que se le han reconocido; "por supuesto, el río en sí mismo no puede litigar ante tribunales o comprar tierras, por lo que la Ley Te Awa Tupua crea un representante, llamado 'Te Pou Tupua', que debe actuar en interés del río" (Macpherson \& O’Donnell-2017, p. 110).

Estos representantes o también llamados guardianes del río - como lo veremos en la jurisprudencia colombiana - están conformados por un representante de Gobierno y por supuesto por un representante de la población Iwi o del mismo río, el reconocerse que son una misma persona y serán ellos, quienes a nombre del río acudan - bajo la figura de legitimación por activa - a los diferentes estamentos estatales en defensa de sus derechos.

No obstante, esta corriente a nuestro juicio de extremo ecocentrismo, al considerar este ecosistema como un ser viviente, tampoco ha sido ajena a las críticas que desde el derecho y la filosofía se puedan presentar, especialmente porque uno de los mayores inconvenientes al momento de reconocer derechos a la naturaleza, resulta el hecho de establecer cuáles son sus intereses, para que los mismos puedan ser representados por las personas designadas para tal fin. De esta manera:

La ausencia de intereses que caracteriza a los 'objetos' naturales, insisten algunos autores, hace imposible conocer lo que es bueno o malo para un objeto y, en ese sentido, conferirle legitimación activa a un objeto es altamente problemático tanto desde una perspectiva jurídica como filosófica. Si yo soy llamado a representar a una montaña, ¿cómo saber si la montaña prefiere mantenerse en su estado natural o ser la sede de un parque de diversiones? (Colón Ríos, 2014, p. 10).

Para entender con mayor claridad esta corriente doctrinaria, habrá que remitirnos a Feinberg (1997), citado en el texto de Colón Ríos (2014), en el que menciona que "solamente aquellos entes que tienen 'intereses', pueden ser titulares de derechos” (p. 2). Esto es fácil de concebir al referirnos a las personas, pues los intereses principales están consagrados en los derechos que garantiza la Constitución Política, como el derecho a la vida, a la salud o a gozar de un ambiente sano; pese a esto, la complejidad se presenta al reconocer los intereses de la naturaleza propiamente, pues será muy difícil definirlos a tal punto de decir que no existen intereses propios de la naturaleza, toda vez que los esfuerzos por conservarla y protegerla indiscutiblemente tienen un ingrediente antrópico; en otras palabras, las protección y conservación de la naturaleza tiene su origen en los intereses de las personas, más aún cuando existen en el mundo ciclos naturales que no dependen del ejercicio de acciones humanas. 


\section{El activismo judicial en materia ambiental}

El papel del juez en la protección del ambiente fue uno de los pilares de la Constitución Política de 1991, tanto es así que el artículo 88 consagra la existencia de las acciones populares, con el propósito de salvaguardar los intereses colectivos relacionados con el ambiente. Esta acción fue posteriormente regulada por la Ley 472 de 1998 siendo la acción por excelencia para defender, como se dijo, los intereses colectivos; de esta manera, si se presenta alguna acción, amenaza u omisión que atente contra el derecho constitucional a gozar de un ambiente sano, será obligatorio acudir a sus disposiciones.

Empero, el desarrollo jurisprudencial ha desarrollado y extendido el derecho a gozar de un ambiente sano, a tal punto de considerarlo fundamental al tener en cuenta su íntima relación con el derecho a la vida, a la vida en condiciones dignas, a la salud, al mínimo vital, entre otros. Ello permite que las personas puedan acudir a la acción de tutela para proteger este derecho, en busca de medidas más eficaces y céleres de las que se pueden encontrar en la acción popular. Con base en lo expuesto, la Corte Constitucional ha dicho:

Cuando se pretenda solicitar el amparo de derechos fundamentales que derivan de la violación de un derecho que, en principio, puede ser concebido como colectivo, el juez constitucional debe ser especialmente cuidadoso al momento de determinar si la acción procedente es la acción popular o la acción de tutela. Así, el hecho de que se pretenda la protección de un derecho colectivo no implica, per se, la improcedencia de la acción de tutela, toda vez que pueden existir circunstancias que hacen necesaria la intervención urgente e inmediata del juez de tutela. La jurisprudencia de la Corte ha fijado los criterios que permiten establecer la procedencia excepcional de la acción de tutela en tales eventos, así: (i) que exista conexidad entre la vulneración del derecho colectivo y la violación o amenaza de un derecho fundamental, de tal forma que el daño o amenaza del mencionado derecho sea consecuencia inmediata y directa de la perturbación del derecho colectivo; (ii) el demandante debe ser la persona directa o realmente afectada en su derecho fundamental, pues la acción de tutela es de carácter subjetivo; (iii) la vulneración o la amenaza del derecho fundamental debe estar plenamente acreditada; (iv) la orden judicial que se imparta en estos casos debe orientarse al restablecimiento del derecho de carácter fundamental y 'no del derecho colectivo en sí mismo considerado, pese a que con su decisión resulte protegido, igualmente un derecho de esa naturaleza'; (v) adicionalmente, es necesario la comprobación de la falta de idoneidad de la acción popular en el caso concreto. (Corte Constitucional, Sentencia T-341 de 2016).

En este contexto, si las personas logran acreditar las cinco condiciones planteadas por el juez constitucional, podrán acudir a la acción de tutela como mecanismo principal para proteger un interés colectivo como el ambiente. Esta ha sido la tesis que permitió la expedición de las sentencias que se analizarán a continuación — solo tres (3) de las ya numerosas sentencias-, las cuales dentro de su ratio decidendi han declarado a ciertos ecosistemas como sujetos de derechos, pese a que tal designación no tenga ninguna base en la Constitución Política vigente. 


\subsection{Corte Constitucional, Sentencia T-622 de 2016}

Esta sentencia marca un antes y un después en la historia de la personalidad jurídica de la naturaleza en Colombia, siendo ella la primera en declarar a uno de los afluentes hídricos más importantes del país - el río Atrato-, como un verdadero sujeto de derechos, a consecuencia de los grandes impactos generados por actividades mineras y de aprovechamiento forestal sin permiso o autorización alguna, dentro de las áreas de influencia.

En ese orden, el contexto social, en el cual se justifica la presentación de la acción de tutela, da cuenta del uso indiscriminado de distintos métodos de extracción minera - aluvión y vetay del aprovechamiento forestal, los cuales vertían sobre el río Atrato y sus afluentes sustancias tóxicas como el mercurio, ocasionando no solo una afectación al ecosistema sino también al bienestar, la cultura, la salud y la vida de los habitantes aledaños al ecosistema. Por lo tanto, los accionistas - organizaciones populares - solicitaron la protección de los derechos a la vida, la salud, el agua, la seguridad alimentaria, el medio ambiente sano, la cultura y al territorio de las comunidades, frente a la omisión de las autoridades nacionales en su deber de controlar este tipo de situaciones.

Dentro de las órdenes impuestas por la Corte Constitucional - título de resumen - se extrae: (i) declaración del río Atrato como como una entidad sujeta de derechos, (ii) conformación de comisión de guardianes del río - una propuesta que luego sería adoptada, como lo revisamos en el caso de Nueva Zelanda-, (iii) plan de descontaminación, (iv) erradicación de minería ilegal en el río Atrato y en el departamento del Chocó, (v) plan para recuperar las tradiciones de subsistencia y alimentación, entre otras (Corte Constitucional, Sentencia T-622 de 2016).

Conforme a ello, la Corte Constitucional implementa una idea revolucionaria a la concepción tradicional de categoría civilista sobre quienes deben ser sujetos de derechos en Colombia y por primera vez, un río debe ser considerado en Colombia no solo como un sujeto de especial protección, sino también como un verdadero sujeto de derechos.

De acuerdo con el análisis de Guzmán Jiménez \& Ubajoa Osso (2020), la Corte Constitucional llegó a esta conclusión en razón a la aplicación del principio de precaución, al tener en cuenta las sustancias tóxicas como el mercurio, las cuales se vertían sin control alguno en la cuenca del río, circunstancia que puede afectar el ecosistema y la salud de los habitantes. Al mismo tiempo, por dar mayor importancia a la visión ecocéntrica - la cual se explicó al inicio de este trabajo-, ello quiere decir que se respeta a la naturaleza por su valor intrínseco y no instrumental; es decir, no por los beneficios que ella pueda generar a las personas, sino por su valor independiente enmarcado por un sinnúmero de especies fácilmente individualizables que tienen derecho a su protección y conservación.

Una de las mayores críticas a la decisión de la Corte Constitucional, por supuesto enmarcada en las mejores intenciones en defensa del ambiente, resulta ser la afectación al derecho al trabajo de miles de personas que dependen de la explotación minera - ilegal - en la cuenca 
del río Atrato, pues de alguna manera la afectación a este derecho genera como consecuencia la vulneración al derecho a su mínimo vital y móvil, al tener en cuenta las escasas oportunidades laborales en la región y lo costoso que implica para estas personas acceder a la minería para cumplir con las exigencias legales.

Un informe realizado por la Defensoría del Pueblo en el año 2016 — en el mismo año de la expedición de la Sentencia- da cuenta:

[...] que el conflicto armado que existe en la zona, la baja capacidad de las entidades y sumado a la actividad migratoria de la propia actividad minera, hace imposible que las entidades territoriales no tengan cifras exactas del número de dragas que operan en el Departamento. (Defensoría del Pueblo, 2016, p. 62).

Todo ello, sin la intención de ser pesimista en la protección ambiental, cuya finalidad persigue la Sentencia T-622 de 2016, hace que sea muy difícil que a través de una declaración del río como sujeto de derechos, que las personas y la propia naturaleza tengan la garantía de una protección efectiva del ecosistema, pues estas personas encuentran su sustento en la minería ilegal; por esta gnosis, aún si se logra articular a las entidades territoriales y las de orden nacional para adelantar todas las acciones dispuestas en la parte resolutiva de la jurisprudencia en mención, extraña y se echa de menos la omisión de alguna directriz encaminada al fomento de la educación ambiental en la región, como un pilar fundamental para la protección del ambiente. Recordemos que:

La educación ambiental es la única manera de lograr la concienciación humana respecto del hecho de que los daños ambientales no son otra cosa que lesiones a los propios seres humanos. Esta concienciación es lo que producirá el cambio de los humanos con respecto a la forma de ver la naturaleza, que ya no sería aquello que se puede explotar sin ningún tipo de límite, sino lo que hay que amparar para asegurar la autoprotección. Y este cambio en la manera de concebir el entorno natural será el que generará la modificación de la conducta humana ante el medio ambiente que será más respetuosa y responsable. (Guzmán Jiménez \& Ubajoa Osso, 2020, p. 210).

En esa medida, la Corte Constitucional falla en sus intenciones de proteger y salvaguardar el ambiente, pues incluso ante la efectividad de los planes de descontaminación y erradicación de la minería ilegal, si no se modifica la manera de pensar de las personas, en relación con la importancia de la naturaleza de la vida de los seres humanos, seguramente sus efectos nocivos volverán en el tiempo.

\subsection{Corte Suprema de Justicia, Sala de Casación Civil, 5 de abril de 2018, STC4360-2018}

Dos años después de la Sentencia que protegió el río Atrato, la Corte Suprema de Justicia decide continuar con el hilo conductor establecido por su homólogo constitucional, e impone a la Amazonia la condición de sujeto de derechos. En esta ocasión un grupo de 25 personas, entre niños, niñas y jóvenes, solicitan la protección de sus derechos a la vida, a la salud y a gozar de 
un ambiente sano, conforme al incumplimiento del Gobierno Nacional de los compromisos adquiridos en el acuerdo de París, especialmente en lo relacionado con la reducción de la deforestación, siendo la Amazonía colombiana una de las más afectadas con este flagelo.

Según los tutelantes, este impacto ambiental además genera la alteración del ciclo del agua, la alteración de los suelos, cambios en el suministro del agua y aumenta el cambio climático (Corte Suprema de Justicia, Sala de Casación Civil, stc4360-2018).

No obstante, esta Sentencia, a diferencia de la T-622 de 2016, lejos de dar un lugar preponderante y exclusivo a la visión ecocéntrica, modifica esta concepción a un criterio "ecocéntrico-antrópico, cuya finalidad es evitar el trato prepotente, displicente e irresponsable del recurso ambiental y de todo su contexto, para satisfacer fines materialistas, sin ningún respeto proteccionista o conservacionista" (Corte Suprema de Justicia, Sala de Casación Civil, stc43602018). Hecho que, sin duda, elimina cualquier posición radical, acepta que las personas puedan satisfacer sus necesidades bajo el uso de los recursos naturales, pero al mismo tiempo construye una barrera para garantizar que esa explotación sea racional y respete a la naturaleza en general.

Por otro lado, del texto de la Sentencia también es posible observar un mal uso del principio de precaución, pues como bien se sabe este principio es utilizado en el evento de existir incertidumbre técnica o científica que pueda generar impactos ambientales; sin embargo, del acervo probatorio se desprende una serie de documentos que dan cuenta del aumento de la desforestación en Colombia y específicamente en la Amazonía, bajo la autoría de autoridades nacionales como el Instituto de Hidrología, Meteorología y Estudios Ambientales (IDEAM); en ese sentido, no era dable utilizar o aplicar la precaución; por el contrario, su deber de protección ambiental se debió justificar en el principio de prevención, al tratarse de un hecho cierto y comprobado por los documentos científicos expuestos.

Pese a que la Corte Suprema de Justicia señala la necesidad de valorar a la naturaleza intrínsecamente, la motivación de la declaración como sujeto de derechos solo encuentra su argumento en la omisión de las obligaciones de las instituciones públicas, como las corporaciones autónomas regionales, parques nacionales naturales y los municipios con jurisdicción en este territorio. Esta Sentencia tampoco prevé un plan de fomento de la educación ambiental; por tanto, su efectividad por ahora será una mera expectativa.

\subsection{Tribunal Superior de Distrito Judicial de Ibagué, Sala Laboral, 15 de septiembre de} 2020

Era cuestión de tiempo para que, en el ámbito regional, la preocupación por la defensa del ambiente se hiciera más común en el sistema judicial; en este caso, una acción de tutela interpuesta para la protección de los derechos a la vida, a la vida en condiciones dignas, al agua, al ambiente sano, entre otros, y la declaración del Parque Nacional Natural Las Hermosas como un sujeto de derechos. Según el actor, este ecosistema ha sufrido de deforestación y fragmentación ecológica 
a causa de actividades antrópicas, con la aquiescencia, falta de control, ausencia de coordinación y omisión de las autoridades ambientales.

El máximo tribunal de justicia de la ciudad plantea la tesis de declaración de la naturaleza como sujeto de derechos en el interés internacional y jurídico para cuidar la naturaleza y la biodiversidad, junto a la que se define como constitución ecológica y en varios apartados de la Sentencia T-622 de 2016.

Si bien el grado de afectación que se demostró en el proceso solo fue de un $2.2 \%$ en la totalidad del ecosistema, el Tribunal falló en favor del tutelante con ocasión a la nula coordinación existente entre las autoridades - pues cada una de ellas entregó detalles de sus acciones- y esto, según el juzgador, es suficiente para considerarlo una amenaza a los derechos de especial protección. Discrepamos de este argumento, pues mediante esta decisión se desconoce el esfuerzo de cada una de las entidades en defensa de este ecosistema, más aún cuando el grado de afectación es tan mínimo que supone el ejercicio de actividades propias de los habitantes que dependen tradicionalmente del parque.

Finalmente, el Tribunal ordena llevar el grado de degradación a cero, hecho que sin duda es imposible sin afectar los derechos de las personas que tradicionalmente lo habitan, pues no es factible desconocer su presencia durante varios años.

\section{El conflicto entre los derechos de la naturaleza y los derechos de las personas}

Al tener claro los conceptos de las corrientes antropocéntricas y ecocéntricas, el estado actual de la personalidad jurídica de la naturaleza en el derecho comparado y la línea de decisiones expuestas por las altas cortes en Colombia, en las que quedó marcada la postura ecocéntrica de la Rama Judicial, la pregunta que surge es: ¿existe conflicto entre los ya reconocidos derechos de la naturaleza y los derechos de las personas?

Recordemos como en la Constitución Política de 1991 se encuentra claramente regulado el derecho de las personas a gozar de un ambiente sano y los deberes tanto de las autoridades públicas como de los particulares en pro de garantizar las mejores condiciones de la naturaleza. Con base en ello, resulta sencillo determinar el alcance de este tipo de derechos en el ordenamiento jurídico, toda vez que su protección es posible frente aquellos eventos que ocasionen o amenacen los ecosistemas propiamente y otros derechos de las personas, como la vida y la salud.

A pesar de lo anterior, determinar el alcance y el impacto los derechos propios de la naturaleza por ahora no es posible; primero, porque las decisiones judiciales analizadas no traen consigo un catálogo de derechos que le pertenecen a la naturaleza; segundo, porque en la mayoría de estas decisiones se tomaron con base en las afectaciones que en el presente y en el futuro se puedan ocasionar en los seres humanos y tercero, porque como lo revisamos anteriormente, tampoco es posible determinar el interés de la naturaleza, al no poderla considerar como un ente racional. 
Esta teoría se refuerza en el entendido que los derechos subjetivos son un conjunto de prerrogativas que el sujeto portador puede promover y desarrollar. En ese sentido, la naturaleza pese a ser reconocida como una persona jurídica bajo la ficción jurisprudencial, no los puede ejercer de manera independiente (Viciano Pastor, 2019). Esto, sin duda, contraría la filosofía ecocéntrica en la intención de otorgar derechos a la naturaleza y nos ubica nuevamente en la esfera antrópica, dentro de la cual la protección ambiental depende estrechamente la intención de los seres humanos, lo cual no significa una desprotección propia de la naturaleza; recordamos que, desde la Constitución Política, es un deber de los particulares "proteger los recursos culturales y naturales del país y velar por la conservación de un ambiente sano" (Constitución Política de Colombia, 1991).

La segunda razón por la cual se presenta un conflicto entre los derechos de la naturaleza y los de las personas, es por el deber de ponderación a cargo del funcionario judicial al momento de decidir quién tiene más relevancia:

A pesar del marcado carácter antropocéntrico de la concesión de personalidad jurídica al entorno natural, una pugna entre los derechos de los seres humanos y los del medio ambiente que puede ser resuelta a favor de este y, por consiguiente, en perjuicio de aquellos. La mera existencia de esta posibilidad desvaloriza los derechos de los humanos. (Guzmán Jiménez \& Ubajoa Osso, 2020, p. 189).

Veamos como este pensamiento no está alejado de la realidad, en el caso del río Atrato si bien compartimos la decisión de proteger el ecosistema de aquellas actividades ilegales que generan impacto negativo, también es claro que la concesión de derechos a la naturaleza está por encima del modelo laboral tradicional de esta región, con ello no pretendemos justificar actividades como la minería ilegal, pero sí reconocer la desprotección de la que fueron objeto estas personas, al tener en cuenta las escasas oportunidades laborales en la región, circunstancia aquella que no se tuvo en cuenta en la decisión de la Sentencia y que, al mismo tiempo, vulnera el derecho al mínimo vital y móvil de la población. De igual manera, ocurre en la Sentencia con el ecosistema de páramos Las Hermosas, que fuera declarado como sujeto de derechos y dentro de la cual se ordenó reducir la degradación a cero, pues aceptar esta orden enmarcada de buenas intenciones, pero irresponsable, es desconocer la presencia de campesinos que tradicionalmente habitan este territorio y dependen exclusivamente del ecosistema.

Por estas razones, consideramos que la sola declaración de personalidad jurídica de la naturaleza no es garantía de una mayor protección; por el contrario, sí genera mayores inconvenientes en los esfuerzos de las autoridades públicas por conservar y proteger los recursos naturales, procesos que han desarrollado a lo largo de los años por mandato constitucional y legal.

Las órdenes impuestas por sentencias no son novedosas - por demás difusas - ni están por encima de la legislación colombiana que pretende conservar y proteger el ambiente, el problema radica en que su ejecución depende exclusivamente de los seres humanos; por tanto, no se trata de sobreponer a la naturaleza a la fuerza - pues bien sabemos que su efectiva protección garantiza la existencia de la especia humana- sino de crear conciencia en todas las personas 
para cambiar la mentalidad y reconocer que todo impacto a la naturaleza se verá reflejado en la salud y la calidad de vida.

Se insiste que el ordenamiento jurídico colombiano cuenta con normas y regulaciones fuertes, estables y conformes a estándares internacionales, empezando por los derechos consagrados en la Constitución Política y los tratados adoptados, que hacen parte del bloque de constitucionalidad, para proteger a toda la naturaleza en general, sin la necesidad de una declaración de sujeto de derechos, que en últimas se reduce a un llamado de atención o una protección simbólica dentro de una respuesta del actuar jurisdiccional.

\section{Conclusiones}

Primera: existen dos corrientes globales a partir de las cuales se realiza la protección a la naturaleza en general, hablamos de ecocentrismo y antropocentrismo; la primera de ellas, en la que se valoran todos los recursos naturales de manera intrínseca; es decir, por su sola existencia debe ser objeto de protección y la segunda, en la que el ser humano se convierte en el centro de atención, con la capacidad de explotar los recursos naturales de manera controlada. La Constitución Política de Colombia guarda características propias del antropocentrismo, al tener en cuenta que permite el acceso de los seres humanos a los beneficios de los recursos naturales, pero al tiempo limita cualquier tipo de actividad, en el sentido de salvaguardar y garantizar un ambiente sano en el territorio.

Por el contrario, las altas cortes en Colombia a través de sus diferentes pronunciamientos han intentado modificar la concepción antrópica del país, al reemplazarla por la corriente ecocéntrica, otorgándole mayor relevancia - como debe ser- a los recursos naturales disponibles; sin embargo, somos claros en señalar que la protección del ambiente solo se da en la medida que cualquier impacto que se pueda ocasionar, se verá reflejado en la salud y en la vida de los seremos humanos; es decir, se protege a la naturaleza no por su valor propio sino por su importancia para garantizar la existencia de la raza humana.

Pero más allá de adoptar una posición a favor o en contra de una de esas corrientes, los impactos ecológicos existen y es deber no solo de las autoridades públicas sino de todos los ciudadanos, actuar de tal manera que en todas las actividades que se desarrollen en el planeta, la prioridad sea la protección y conservación de los recursos naturales.

Segunda: el fenómeno de la personalidad jurídica de la naturaleza está presente en el derecho comparado, a tal punto que su reconocimiento no solo ha sido jurisprudencial, sino de carácter constitucional y legal, como en los casos de Ecuador y Nueva Zelanda. Aun así, su regulación no ha sido pacífica, pues ha sido objeto de múltiples críticas, especialmente por aquellas en las que se expresa que la protección de la naturaleza al final solo se da en virtud de los impactos que se ocasionan a las personas afectadas, hecho que estaría regulado en la legislación de esos países con los llamados derechos ambientales, lo cual acarrea una protección simbólica de los derechos propios de la naturaleza. 
Tercero: desde el año 2016 se han expedido en Colombia numerosas sentencias en las que se reconoce a la naturaleza como un verdadero sujeto de derechos, este evento se ha replicado a tal punto que hoy no es extraño encontrar por lo menos un ecosistema específico, objeto de protección en las diferentes regiones del país.

$\mathrm{Si}$ bien, con estos pronunciamientos han querido realizar un llamado de atención a toda la población, pero especialmente a las autoridades sobre la importancia de la protección de la naturaleza, por ahora no son más que una mera expectativa, toda vez que no existen datos científicos o técnicos que permitan establecer un mayor grado protección en relación con la legislación ambiental existente en el país. Desde este punto de vista, señalamos que la protección ambiental no puede ser simbólica; por el contrario, una verdadera protección ambiental se caracteriza principalmente por la efectividad, por los cambios en el territorio y la garantía de un ambiente sano.

De ahí la necesidad - como se dijo previamente- de fortalecer la educación ambiental, este será el único proceso que permitirá cambiar la mentalidad de los seres humanos, la acción debe ser articulada entre todos los sectores e iniciar desde los grados más pequeños de educación e incluso extenderse a los niveles más altos de educación profesional, solo de esta manera los seremos humanos entenderemos que todos los impactos ambientales tendrán consecuencia en la vida de quienes habitamos el planeta.

Por otro lado, no es pertinente la declaración de la naturaleza como sujeto de derechos, porque a partir de las órdenes de los jueces se está reemplazando la tarea del Ejecutivo en la gestión y planificación ambiental. Obligación que puede ser desproporcional y difusa si no se cuenta con los conocimientos científicos necesarios y, ocasionalmente, hasta puede acarrear mayores impactos, pues los jueces en su mayoría no son expertos en temas ambientales, más allá de su preocupación racional por la naturaleza.

Ajustado a lo anterior, planteamos la necesidad de fortalecer las políticas ambientales del Estado y superar ese déficit de confianza, para hacer uso de las herramientas disponibles de protección de la naturaleza.

Cuarto: la declaración de la naturaleza, como un verdadero sujeto de derechos, crea conflictos con los derechos de las personas, pues el solo hecho de tener que decidir en determinado caso por la prevalencia del primero, resta valor a los seres humanos; en ese orden, no se trata de situar a la naturaleza por encima de las personas, ni mucho menos a las personas como núcleo esencial; por el contrario, la tarea permanente debe buscar un equilibrio que permita que las personas puedan tener acceso a los recursos naturales, con la estricta observación de estándares de conservación y protección.

Desde este trabajo, expresamos que toda la naturaleza, los recursos naturales renovables y los no renovables, merecen el mismo trato e importancia, ello quiere decir que no por el hecho que un determinado ecosistema sea declarado como sujeto de derechos, merece o tendrá mayor protección que uno que, a la fecha y con sus mismas características, no lo sea. 


\section{Referencias}

Amaya Navas, O. D. (2016). La constitución ecológica de Colombia (3. ${ }^{a}$ ed.). Bogotá, Colombia: Universidad Externado de Colombia.

ввс News. (16 de marzo de 2017). Whanganui, el río en Nueva Zelanda que tiene los mismos derechos que una persona. BBC Mundo. Recuperado de https://www.bbc.com/mundo/noticias-39291759

Colón-Ríos, J. I. (2014). Naturaleza, legitimación activa y el río Whanganui. Trabajo presentado en el Seminario Internacional Derechos de la Naturaleza: Aplicación y tendencias Guayaquil, Ecuador (diciembre, 2012). Recuperado de http://dx.doi.org/10.2139/ssrn.2883886

Congreso de la República. (6 de agosto de 1998). Ley que desarrolla el artículo 88 constitucional, Ley 472 de 1998.

Constitución Política de Colombia. (1991). Bogotá, Colombia: Panamericana.

Constitución de la República de Ecuador. (2008). Quito, Ecuador: Librería Nacional.

Dávila, D. (2011). Modernidad: Fractura de la relación sociedad-naturaleza. En Conde, A., Ortiz P. A., Delgado, A., Gómez, F., \& Granados, L. R. (Coords.). Primer Congreso Nacional de NaturalezaSociedad, (pp. 76-95). Tlaxcala, México: Universidad Autónoma. Recuperado de https://www.aacademica.org/alberto.conde.flores/5.pdf

De Souza Abreu, I., \& De Azevedo Bussinguer, E. C. (2013). Antropocentrismo, ecocentrismo y holismo: Un breve análisis de las escuelas de pensamiento ambiental. Derecho y cambio social, (34), 1-11. Recuperado de https://www.derechoycambiosocial.com/revista034/escolas_de_pensamento_ambiental.pdf

Defensoría del Pueblo Colombia. (2016). La minería sin control. Un enfoque desde la vulneración de los derechos humanos. Bogotá, Colombia: Imprenta Nacional de Colombia. Recuperado de https://www.defensoria.gov.co/public/pdf/InformedeMinerIa2016.pdf

El País. (16 de marzo de 2017). Nueva Zelanda reconoce un río como persona jurídica. Recuperado de https://elpais.com/internacional/2017/03/16/actualidad/1489685532_492954.html

Guzmán Jiménez, L. F., \& Ubajoa Osso, J. D. (2020). Reconocimiento de la naturaleza y de sus componentes como sujetos de derecho (1.a ed.). Bogotá, Colombia: Universidad Externado de Colombia.

Macpherson, E., \& O'Donnell, E. (2017). ¿Necesitan derechos los ríos? Comparando estructuras legales para la regulación de los ríos en Nueva Zelanda, Australia y Chile. Revista de Derecho Administrativo Económico, (25), 95-120. Recuperado de http://ojs.uc.cl/index.php/REDAE/article/view/3508

Martínez Torvisco, J. (2011). La ética ambiental y su relación con la sostenibilidad. Ingurauk. Revista Vasca de Sociología y Ciencia Política, (48-49), 31-40.

Semana. (30 de marzo de 2017). El río que tiene los mismos derechos de una persona. Revista Semana. Recuperado de https://bit.ly/2Po8STo

Sentencia T-622 de 2016. Corte Constitucional de Colombia. Magistrado Ponente: Jorge Iván Palacio Palacio.

Sentencia T-341 de 2016. Corte Constitucional de Colombia. Magistrado Ponente: Gabriel Eduardo Mendoza Martelo. 
Sentencia STC 4360-2018. Corte Suprema de Justicia de Colombia. Magistrado Ponente: Luis Armando Tolosa Villabona.

Sentencia 11121-2011-0010. (30 de marzo de 2011). Corte Provincial de la Loja de Ecuador.

Toca Torres, C. E. (2011). Las versiones del desarrollo sostenible. Sociedade e Cultura, 14(1), 195-204. https://doi.org/10.5216/sec.v14i1.15703

Viciano Pastor, R. (2019). La problemática constitucional del reconocimiento de la naturaleza como sujeto de derechos en la Constitución del Ecuador. En L. Estupiñán Achury, C. Storini, R. Martínez Dalmau \& F. A. De Carvalho Dantas, La naturaleza como sujeto de derechos en el constitucionalismo democrático (1.a ed.), (pp.137-154). Bogotá, Colombia: Universidad Libre. https://doi. org/10.18041/978-958-5578-09-8

\section{Bibliografía recomendada}

Corona, E. (2012). Los retos del desarrollo sustentable y sus interacciones con la cultura. El Tlacuache, (525), 1-4. Recuperado de https://mediateca.inah.gob.mx/repositorio/islandora/object/ issue $\% 3 \mathrm{~A} 2342$

López Vargas, S. L., Hernández Albarracín, J. D., \& Méndez Castillo, C. S. (2019). Desarrollo jurisprudencial de la protección ambiental en Colombia: Aportes desde la perspectiva neoconstitucionalista. Opera, (24), 49-65. https://doi.org/10.18601/16578651.n24.04

Macías, L. F. (2018). ¿Qué significa que la amazonia sea un sujeto de derechos? Revista Colombia Amazónica, (11), 103-120. Recuperado de https://bit.ly/3rhv0Nn 